\title{
EL PINTOR PERE SERRA I PEDRALBES: NOVES OBRES
}

\author{
FRANCESCA ESPAÑOL I BERTRAN \\ Universitat de Barcelona
}

Fins la segona meitat del segle XIX, a la sacristia del monestir de Pedralbes se servaren unes pintures sobre taula, la qualitat de les quals elogien els diversos historiadors que les van veure. Aquesta opinió no s'ha pogut contrastar mai més, ja que aleshores passaren a mans privades i se n'ha perdut el rastre, fins avui. Tot i comptar amb una reproducció detallada de cadascuna de les cinc escenes que semblen haver ornat el bancal d'un retaule, aquest conjunt pictòric no s'ha tingut mai en compte en els estudis apareguts sobre pintura gòtica catalana. Un fet més que justificat, atesa la manca de qualitat dels dibuixos, obra del Sr. Macari Golferichs ${ }^{1}<$ Figs. 1$2>$. Com reconeix Sanpere i Miquel que fou el primer en publicar-los ${ }^{2}$, tenien un interès més documental que artístic, ja que s'havien fet per a il-lustrar qüestions relatives a la indumentària medieval. Donar-los a conèixer, podria contribuir a identificar el bancal en un futur, però mai serviria per a avançar en el camí de la seva anàlisi estilística ${ }^{3}$.

\footnotetext{
'Aquests cinc dibuixos no es conserven entre els que integren el Fons Golferichs de la Biblioteca de Catalunya.

2S. SANPERE I MIQUEL, Els Trescentistes, I ("La pintura Mig-eval catalana" II), Barcelona. s.a. (1920), figs. 94, 95, 96, 97, 98, entre les pp. 259 i 267.

${ }^{3}$ "D'aquest bancal, per raó de la seva indumentaria, el senyor Golferichs ne va treure una nota de color que ha posat a la nostra disposició i que publico per si, mitjançant el seu coneixament, algú'ns diu "jo'l tinc", o bé "el trobaran a tal lloc"; perquè, conegut, qui sab si no podria ser o donar-se com obra primerenca den Jaume Serra, ja que res digués de cap dels 
Això no obstant, la troballa de la reproducció desconeguda d'una de les taules, modifica notablement aquest estat de coses. Continuem ignorant tot el que pertoca a la localització actual de la predel·la, però, com veurem, és possible avançar una atribució per a les pintures a partir d'ella. Es tracta d'una aquarel-la inacabada d'en Pau Milà i Fontanals, integrada en la col-lecció dels seus dibuixos, que fou cedida pel seu germà Manuel a la Reial Acadèmia Catalana de Belles Arts de Sant Jordi de Barcelona ${ }^{4}<$ Figs. 3 i $4>$. A diferencia de la corresponent d'en Golferichs, aquesta és fidel a l'estil originari i revel·la inequívocament la faisó dels germans Serra, els pintors més reputats a Catalunya durant la segona meitat del Trescents.

Abans de presentar l'aquarel·la d'en Milà, resseguirem la història d'aquest bancal en el que cal considerar el seu rastre final: des del moment en el que, ja fora del seu emplaçament primitiu, romania a la sagristia de l'església, fins al moment en que va passar al mercat antiqüari, a les darreries del segle XIX.

El primer que ens en parla és Josep Puiggarí en el seu llibre Garlanda de joyells publicat l'any 1879. L'any 1864 havia pogut entrar dins la clausura del monestir, acompanyant al bisbe de Barcelona i, entre les diverses coses que li cridaren l'atenció, i que descriu, hi ha les pintures referides. Del seu entusiasme n'és testimoni el text que els hi dedica, despres de deu anys: «Tota la fusta del (retaule) major la dariem de bona gana per lo fragmentet de taula gótica que seria la primitiva, formant repartiments ab varias pinturas de gran interés arqueològic, qu'es conservá molt temps en un recó de la sagristia» ${ }^{5}$.

mestres coneguts, puix pel que s'ha dit no'ns trobem, davant dels dibuixos del Sr. Golferichs, amb cap pretensió de memoria de l'obra pictorica, sinó de la seva indumentaria" (Ibidem, pp. 266-267).

${ }^{4}$ Barcelona, Reial Acadèmia Catalana de Belles Arts de Sant Jordi. Fons Milà i Fontanals. Forma part del conjunt de dibuixos de gran format que estan reunits en una mateixa carpeta, sense ordenar. Porta el número 1920 i a l'esquerra de la zona inferior de l'aquarel-la hi figura l'anotació: Pedralbes. Mesura 22,5 x 28, $8 \mathrm{cms}$. Vull agrair des d'aquí a la conservadora del fons, Victòria Durà, totes les facilitats que em va donar per a la seva consulta. Sobre el fons de dibuixos de Pau Milà i Fontanals de l'Acadèmia, vegeu la Tesi de Llicenciatura de $N$. Rivero, Pau Milà y Fontanals. Teoria i praxi, Barcelona, 1983.

${ }^{5} \mathrm{~J}$. PuIgGarí, Garlanda de joyells, Barcelona, 1879, p. 177. Notes redactades 11 anys després de la seva visita al monestir de Pedralbes (1864), acompanyant al bisbe Montserrat i al regent Penyalver, segons ell mateix adverteix ( p. 173 nota 1). D'aquest fragment de retaule se'n torna a parlar poc després (1888) en una guia dels encontorns de Barcelona quan es descriu el monestir de Pedralbes: "El anagrama del nombre de Jesús, con relieves del siglo XV, el escudo señorial empotrado en una pila de marmol y un fragmento de gótico retablo, conservado en la sacristía, tienen condiciones de relevante mérito artístico" (J. FITER INGLÉS, Guícı- 
Dels termes emprats potser pot deduir-se que, en el moment de l'edició del llibre, el seu autor ja tenia constància que les pintures havien sortit de Pedralbes. Ignorem quan s'esdevingué, però és segur que foren cedides a un particular abans de 1890 (més endavant una altre font l'identifica com el canonge barceloní Dr. Vallet $)^{6}$. En tenim la prova en un nou redactat d'en Puiggarí. Com ell mateix assenyala, per a il·lustrar el vestit dels entorns de 1330 en els seus Estudios de indumentaria española concreta y comparada, va servir-se del: «Retablo de Pedralbes, que seria el primero, fecha de la construcción del monasterio. Tomamos nuestros cuadros (martirio de Sta. Catalina, milagros de Sta. Elena y de S. Francisco de Asís), del único fragmento de dicho retablo (predela o bancal) que estuvo largo tiempo arrinconado en aquella sacristía, hoy en manos de un diligente coleccionista. Sus indumentos corresponden al decenio de 1330-1340...» ${ }^{7}$. Puiggarí no solament parlava de la predel-la que estudiem, sino que va publicar-ne els dibuixos de dues de les escenes que la integraven i que reproduim < Fig. $5>$.

Pel que fa a l'identitat d'aquest col-leccionista, la descobreix Sanpere i Miquel, en el paràgraf més extens que s'ha dedicat a aquest bancal i que s'inclou en el primer volum de Els Trescentistes publicat l'any 1920: "Guardava Pedralbes, fins no fa gaires anys, un bancal d'un retaule desaparegut; i aquest bancal, les monges, en agraiment de lo que'l Dr. Vallet, canonge de la Catedral de Barcelona, havia fet per elles, li van regalar. Més el nostre canonge no'l va guardar, sinó que'l va vendre a un

Cicerone. Las cercanías de Barcelona, Barcelona, 1888, pp. 49-50).

${ }^{6} \mathrm{El}$ període anterior a 1884 fou especialment nefast pel patrimoni del monestir. Un decret episcopal del 24 de maig d'aquell any va acabar per prohibir la venda dels objectes que li pertanyien (Cf. E. ANZIZU, Fulles Històriques de Santa Maria de Pedralbes, Barcelona, 1897, p. 200). El mal, però, ja estava fet. En parla en dues ocasions el propi Sanpere i Miquel: «dicha señora (Sor Eulalia Anzizu) que tanto ha hecho por la restauración de Pedralbes y tan celosa está de sus glorias y monumentos, del cual no hubiera salido lo mucho y bueno que del mismo salió hará unos veinticinco años, o poco más, de haber estado ya ella en el monasterio» ( $S$. SANPERE Y MIQUEL, Los cuatrocentistas catalanes, vol. I, Barcelona, 1906, p. 194). Escriu en una altra ocasió: "Clar està que lo conservat fins avui en dóna gran recança per lo perdut; i lo perdut no de l'antigor, sinó dels nostres dies, puix al costat de casa meva, a casa dels germans Moliné, en el carrer del Comte del Asalto, 22, bé se'n vengueren, publicament, de coses d'art del monestir de Pedralbes!» (S. SANPERE I MiQuel, Els Trescentistes, I, p. 174)

${ }^{7} \mathrm{~J}$. PUIGGARÍ, Estudios de indumentaria española concreta y comparada, Barcelona, 1890, p. 378 , làmina 25 , en la qual es reprodueixen els episodis de la troballa de la Santa Creu per Santa Elena i el martiri de Santa Caterina, sense que hi consti, però, el seu emmarcament arquitectònic, de manera que s'obvien els escuts del promotor emplaçats a banda i banda d'aquest, ben visibles, en canvi, en els dibuixos d'en Golferichs. 
antiquari que hi havia a la plaça del Pi. Si l'hagués guardat, avui el tindriem a la Sala Capitular de la Catedral barcelonina, on han anat a parar les restes de les seves col-leccions d'antiguitats, per ell deixades al Capitol de que havia format part» ${ }^{8}$.

Abans de 1890, per tant, aquestes pintures van passar a mans particulars i amb anterioritat a 1911 al mercat antiqüari. Fem aquesta darrera afirmació emparant-nos en les notícies que proporciona Mossèn Mas sobre la col·lecció del Dr. Vallet, a la guia de la catedral de Barcelona publicada l'any $1916^{9}$. Com a testimoni per a la historiografia, restaren, però, els dibuixos d'en Golferichs publicats el 1920 per Sanpere i Miquel, i les reproduccions que va fer i publicà d'una part del conjunt Josep Puiggarí el '1890. Malgrat tot, les darreres, per raó del contingut del llibre on aparegueren, han quedat al marge de la història de l'art, fins avui ${ }^{10}$. Macari Golferichs reproduí cinc escenes hagiogràfiques corresponents a la descoberta per part de Santa Elena de la Vera Creu, al martiri de Santa Caterina, a un miracle de Sant Francesc i a dos episodis més dificils d'indentificar: el martiri d'un sant bisbe i la possible confirmació de la regla d'una nova orde per part del papa. Posep Puiggarí dibuixà la descoberta de Santa Elena i al martiri de Santa Catalina. Contrastar aquells episodis per als quals disposem de dues reproduccions evidencia la poca voluntat de "còpia" que tenien els seus autors i, alhora, la mediocritat d'un i altre com a dibuixants.

Com s'ha assenyalat, tots aquells que parlen de les antigues pintures de Pedralbes, insisteixen en el fet que es tractava d'un bancal. No estem en disposició de comprovar-b̧o, però els contractes d'altres retaules anterios o contemporanis, així com certes obres catalanes del corrent italianitzant que conservem, certifiquen la freqüència de la fórmula a la qual es va acudir: una sèrie d'escenes hagiogràfiques. Des de Ferrer i Arnau Bassa que en el

${ }^{8}$ S. SANPERE I MiQuel, Els Trescentistes, I, p. 266.

${ }^{9}$ «... desde 1911 esta capilla (la primitiva de Sant Martí de Tours) tiene un caracter de incipiente museo. Lo constituye, por ahora, un barroco retablo del Nacimiento del Salvador, procedente de la testamentaria del canónigo magistral Dr. Valet.." (J. MAS, Guía-Itinerario de la catedral de Barcelona, Barcelona, 1916, p. 109).

${ }^{10}$ En el volum dedicat a Barcelona del Catálogo Monumental de España, per exemple, només es mencionen i reprodueixen els dibuixos de Macari Golferichs. Vegi's: J. AINAUD, J. GUDIOL, F.-P. Verrié, La ciudad de Barcelona ("Catálogo Monumental de España"), Madrid, 1947, p. 147, vol. làmines: figs. 826 a 830 . 
contracte d'un retaule amb Ferrer Peyron el 10 d'abril de l'any $1348^{11}$ convingueren ubicar-hi cinc episodis de la vida de Sant Antoní, fins a diversos retaules com el que, provinent de Castelló de Farfanya, es custodia actualment al Museu Diocesà de Lleida, o els mateixos dels germans Serra ${ }^{12}$.

Recordem que Golferichs, al reproduir les pintures, no deixà de banda l'heràldica que era present a cadascuna de les escenes del bancal. Es tracta d'escuts en losange, situats a banda i banda de l'emmarcament arquitectònic que les aixopluga. Mostren, en el seu camper partit en flangé, els emblemes dels Cruïlles i els Cardona. La documentació del monestir proporciona diversos candidats a promotor del retaule, però cal descartar-ne alguns $^{13}$. Qui sembla reunir, en canvi, totes les condicions, és l'anomenada Constança de Cruïlles, que essent membre del llinatge dels Cardona va casar-se amb Jofre de Cruilles (†1348) i n'adoptà el cognom així com l'heràldica que va dimediar amb la que li corresponia per naixement ${ }^{14}$. Va estar vinculada molt estretament al monestir, com ho atesten les fundacions

\footnotetext{
"El publica: M. TRENS, Ferrer Bassa i les pintures de Pedralbes, Barcelona, 1936, doc. XXXV, pp. 174-175.

'Vegi's: J. Gudiol, S. Alcolea I Blanch, Pintura gòtica catalana, Barcelona, 1986, figs. 18, 22, 24 (color); 261, 265, 305 etc.

${ }^{13}$ Els que ens han precedit en aquest intent d'identificar el promotor del bancal, han emprat com a via d'aproximació l'heràldica, la mateixa que ens serveix a nosaltres. Sanpere i Miquel després d'assenyalar la direcció correcta: «Procedia, evidentment, dit bancal, de la capella de Sant Miquel i Sant Pere, capella construida amb 8.000 sous, deixats amb aquest intent per madona Constança de Cardona, i en la qual, més endevant, sor Constança de Cruilles instituí un benifet perpetual sobre les rendes i censals del castell de Cruilles...", es confon finalment: «Sembla ben clar que's tracta de dues benefactores del monetir: d'Una Constança de Cardona i d'una Constança de Cruilles; més el dir-se una i altra, Constança, ens fa pensar si no podrien ser les dues sors una sola, una Constança de Cardona i de Cruilles, cosa que en principi ningú admetrà, però que tal vegada passi, ja que precisament tenim dit bancal blasonat, puix a cada una de les seves taules surt l'escut dels Cardona-Cruilles. Per aquesta raó he donat el nom dels Cardona-Cruilles al bancal procedent de llur capella» (S. SANPERE I MIQUEL, Els Trescentistes, I, pp. 267-268).

${ }^{14}$ Sobre els Cruïlles en aquest període, vegeu: P. Català, M. Oliva, M. Brasó, "Castell de Cruilles", dins: Els Castells Catalans, II, Barcelona, 1969, pp. 649-660. L'heràldica del llinatge patern de Constança (el card dels Cardona) es reprodueix plena a l'enteixinat que s'incorporà al castell familiar de Peratallada, des de les proximitats de l'any 1931 al MNAC, potser com a commemoració de les seves noces amb Gilabert de Cruïlles. Prové segurament de l'aula super portali castri esmentada l'any 1395 amb motiu de l'aixecament de l'inventari dels bens familiars [Cf. F. ESPAÑoL, La escultura gótico funeraria en Cataluña (s. XIV), Tesis doctoral inédita, Barcelona 1987, vol. I, p. 104].
} 
que hi impulsà ${ }^{15}$ i de les quals se'n fan ressò unes antigues "Ordinacions": «En nom de Déu: en la any de la nativitat de nostre senyor M.CCC.LXI, a XII dies del mes de Janer, la nobla madona sor Constança de Cruiles, muller del noble en Gilabert de Cruiles quondam, menoreta en lo monestir de madona santa María de Pedralbes, estant en habit seglar, a reverencia de nostre senyor Iesu Crist e en remey de ça anima e del noble Bernat de Cruiles fill seu molt car, e de tots ços predecessors feu e institui en lo dit monestir, ço es en la capela dels benayrats sent Miquel e de Sen P... un benifet perpetual sost la forma qui's seguex... ${ }^{16}$. De Constança i de la capella de Sant Miquel i Sant Pere se'n torna a parlar en el necrologi de la casa en aquests termes: "II Kalendas Eodem die et anno domini M (CCC) LXXXVII obiit nobilis Domina et religiosa soror Constancia d'Crudilis que existens in habitu seculari instituit quoddam beneficium seu qumdam presbiteratum in ecclesia huius Monasterii sub invocatione beatorum Michelis Archangeli et Petri apostoli et ordinavit pietantiam fiendam quolibet anno Monialibus, Presbiteris et Fratribus huius monasterii in festo Assumptionis B. Marie et dimisit centum solidos cesualis mortui pro anniversariis fiendis eius annuatiam in fine mensis Augusti per presbiteros et fratres istius monasterii. Et nihilominus dedit huic monasterio unum calicem valde solepnem et quoddam frontale margaritis ornatum et multa alia jocalia cuius anima collocari valeat cum beatis. Amen» ${ }^{17}$.

Quan Constança de Cruïlles abocà la seva manuficència en aquesta fundació, la capella era ja un fet des d'uns anys abans. La bona marxa de les obres de l'església, des de la inauguració del convent l'any 1327, ho fan pressuposar $^{18}$. Datava del període inicial de la vida comunitària, i es fundà per disposició testamentària d'una parenta seva, Constança de Cardona, que hi destinà 8000 sous $^{19}$. La capella, consagrada inicialment només a Sant

\footnotetext{
${ }^{15}$ Ultra les referències que citem en les notes que segueixen vegi's: E. ANZIzU. Fulles Històriques, pp. 60-61.

${ }^{16}$ M. DE CASTRO, Necrologio del monasterio de Sta. $M^{a}$ de Pedralbes (s. XIV), "Hispania Sacra", XXI (1968), pp. 399-400.

${ }^{17}$ Ibidem, p. 408.

${ }^{18}$ Sobre la rapidesa i les característiques de la fàbrica del monestir, vegi's els treballs de F. ESPAÑ̃L i E. ORTOLL, dins: Elisenda de Montcada. Una reina lleidatana i la fundació del Reial monestir de Pedralbes, E. BALASCh i F. EsPañol Eds. Lleida, 1997.

${ }^{19} \mathrm{M}$. DE CASTRO, Necrologio, p. 408: «K(alendis) Marcii. Obiit nobilis Domina Constancia de Cardona, hic sepulta anno Domini M.CCC. vicesimo quinto quo legavit in suo testamento isti monasterio XII millia solidorum barchinonensium videlicet octo milia pro quadam capella
} 
Pere, devia incorporar la segona advocació (Sant Miquel) de la mà dels Cruïlles, ja que, ultra les atribucions com a advocat dels difunts i conductor de les seves ànimes al cel, el monestir fundat dins el senyoriu territorial familiar el tenia per titular. La capella de Pedralbes estava radicada a la banda de l'Epístola, en el sector més proper al presbiteri, i a la clau de volta hi figura l'apòstol de mig cos, amb les claus preceptives, testimoni inequívoc de la correspondència entre l'obra arquitectònica i la fundación ${ }^{20}$.

Constança de Cruïlles va morir l'any 1387. D'ençà de 1348 era vidua i potser no es va retirar a Pedralbes immediatament, però acabà fentho. Una de les referències amb que comptem la indentifica com a «menoreta en lo monestir de madona santa María de Pedralbes, estant en habit seglar» l'any 1361 . Assenyalem aquest fet, ja que per raons que exposarem en el seu moment, l'encàrrec als germans Serra ha de situar-se en les proximitats d'aquesta data, és a dir, en el període ple de la viudetat de Constança.

Les escenes de la predel la que estudiem, reflecteixen una sèrie d'episodis hagiogràfics esparsos sense cap mena d'unitat entre si i absolutament independents de les advocacions adscrites a la fundació del llinatge. D'altra banda, cal reconèixer que mentre el necrologi i l'inventari del monestir realitzat a la mort de la reina l'any 1364, vinculen a la manuficència de Constança una sèrie d'objectes litúrgics, no mencionen per a res aquest retaulet ${ }^{21}$. Tals constatacions ens han empes a planteiar-nos una possibilitat alternativa: que es tractés d'una obra emprada privadament per Constança en els seus exercicis devocionals i que fos destinada en conseqüència a la seva cel·la.

Pau Milà i Fontanals va morir el 1883. Si l'aquarel-la conservada dins el fons que duu el seu nom a l'Academia de Belles Arts de San Jordi li pertany, com creiem, va haver-la de fer entre el moment en que el bancal sortí de Pedralbes i el 1883. En conseqüència, quan formava part de la $\mathrm{col} \cdot$ lecció del Dr. Vallet, moment que aprofitaren al seu torn i amb idèntics motius Golferichs i Puiggarí.

\footnotetext{
ad honorem Sti. Petri Apostoli in ecclesia construenda et quatuor millia solidorum pro domo capitali eiusdem monasterii construenda. Cuius anima requiescat in pace. Amen».

${ }^{20}$ Sobre les claus de Pedralbes: N. BAQUÉ, Les claus de volta de l'església de Santa Maria de Pedralbes, dins: Elisenda de Montcada. Una reina, p. 59 i s. Es reprodueix la que comentem a la fig. 9.

${ }^{21}$ E. Anzizu, Fulles Històriques, p. 76 i ss.
} 

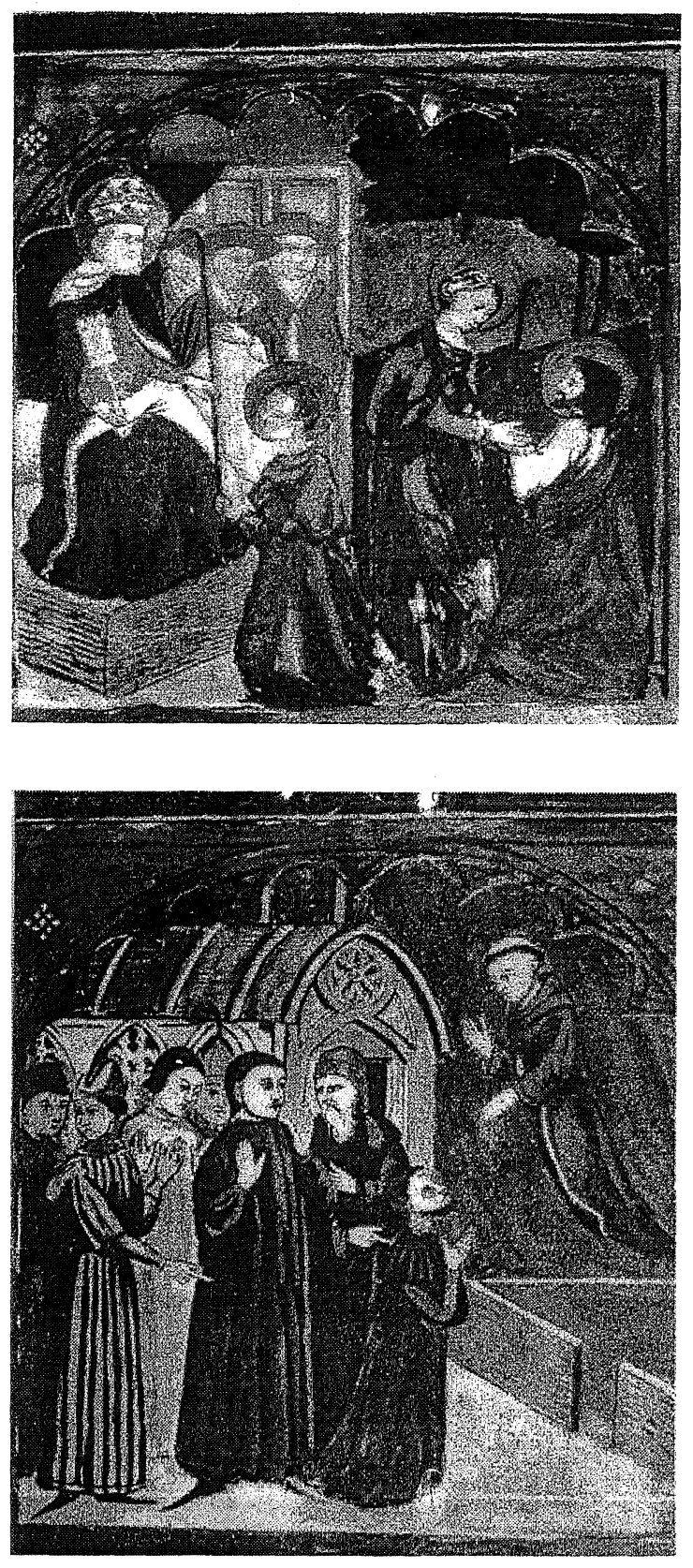

Fig. 1 a) i b) 

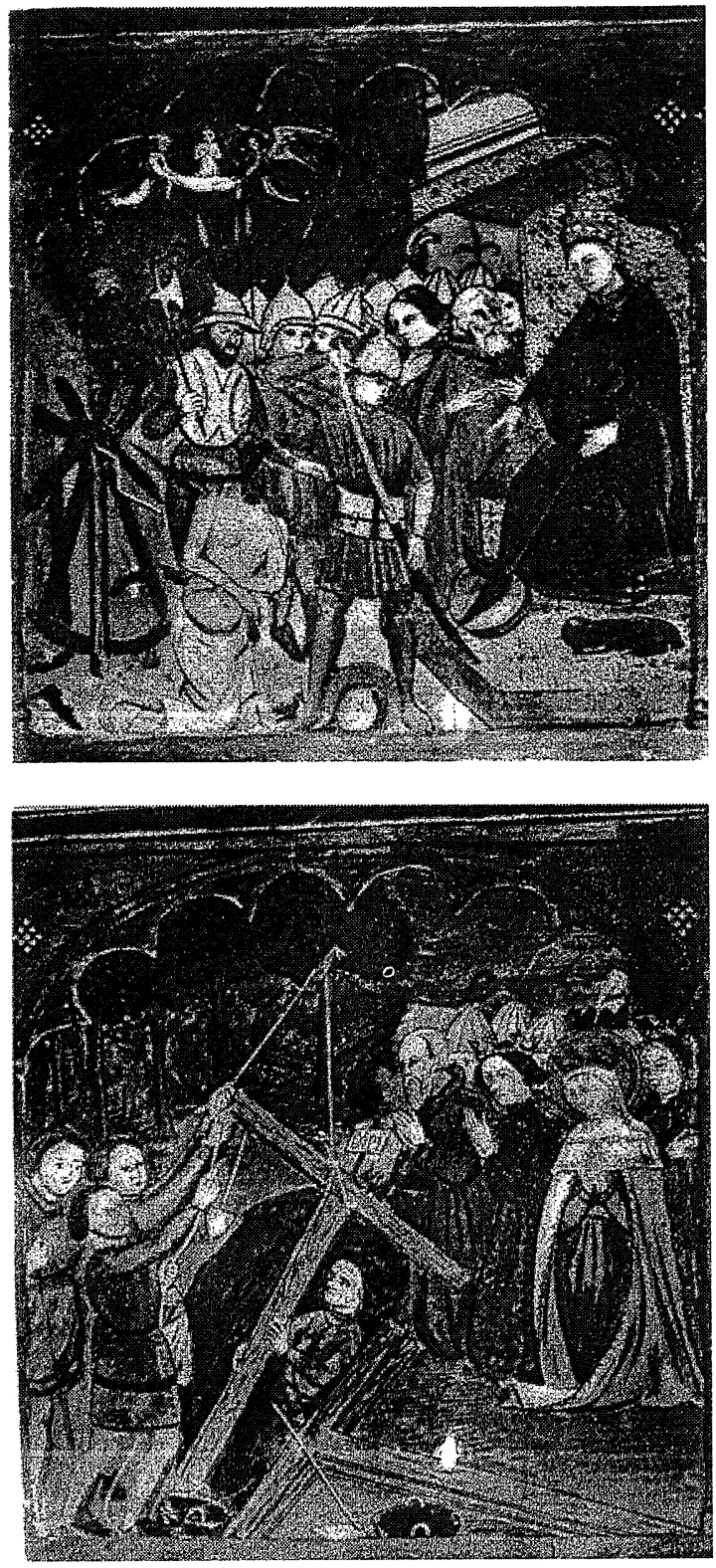

Fig. 1 c) i d)

Predel-la originària del monestir de Pedralbes, de la qual s'ignora la seva localització actual. Dibuixos de Macari Golferichs (ca. 1890-1911). La Col·locació dels episodis hagiogràfics és absolutament arbitrària. 


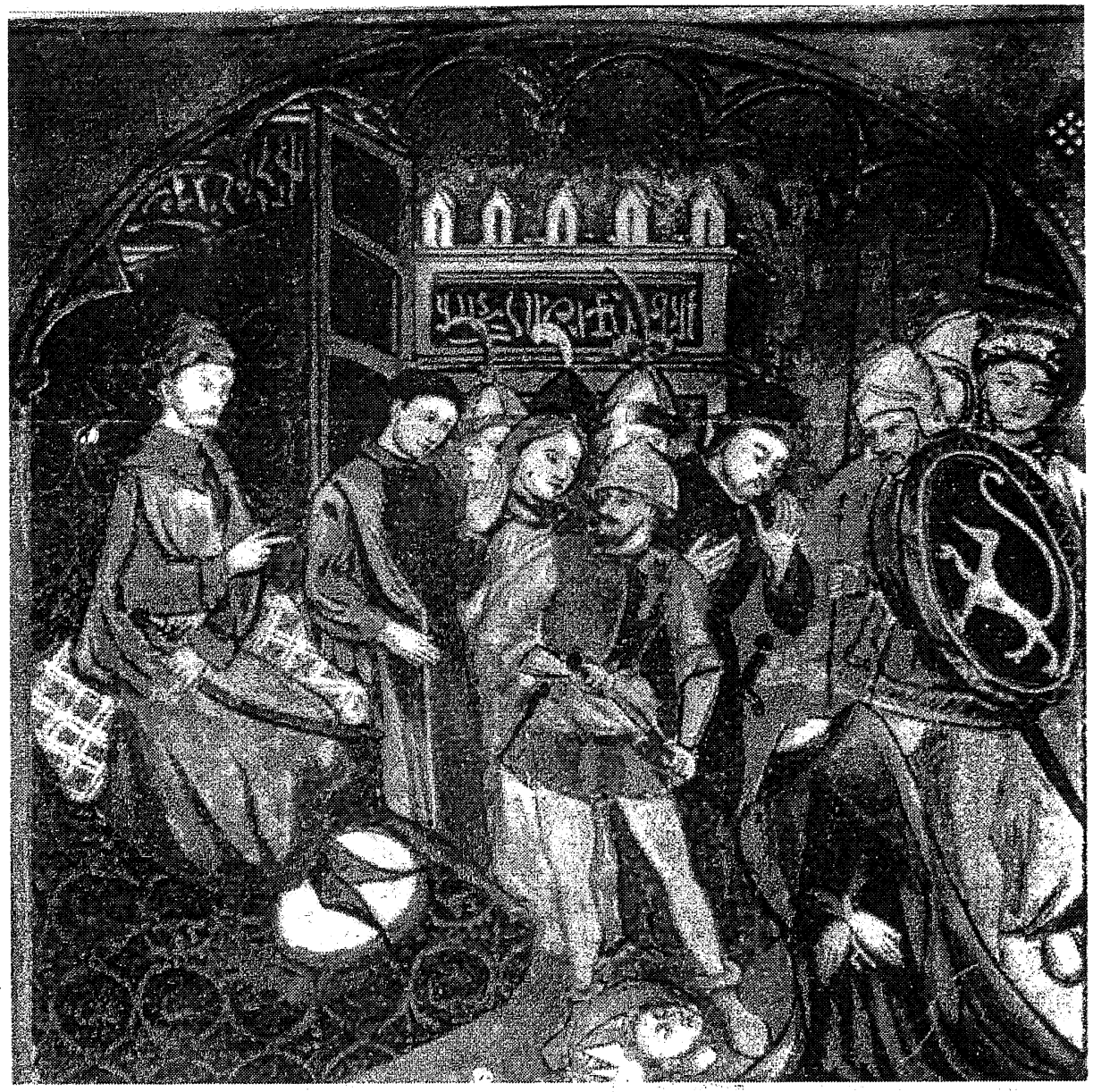

Fig. 2. Macari Golferichs. Detall d'una de les escenes del bancal originari de Pedralbes. Martiri d'un Sant Bisbe. 


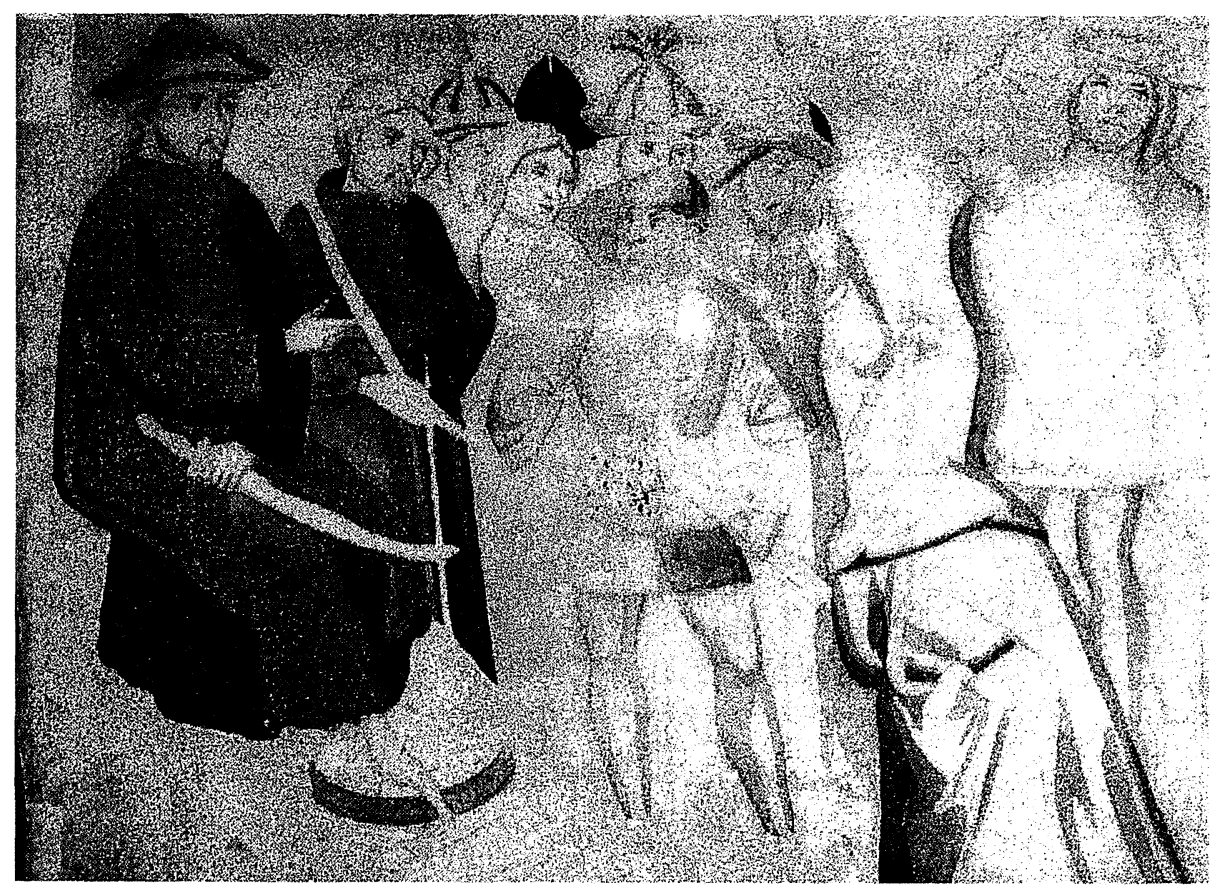

Fig. 3. Pau Milà i Fontanals. Aquarel-la inacabada. Martiri d'un Sant Bisbe de la predel-la de Pedralbes. Barcelona, Reial Acadèmia Catalana de Belles Arts de Sant Jordi. Dibuixos de Pau Milà i Fontanals. 


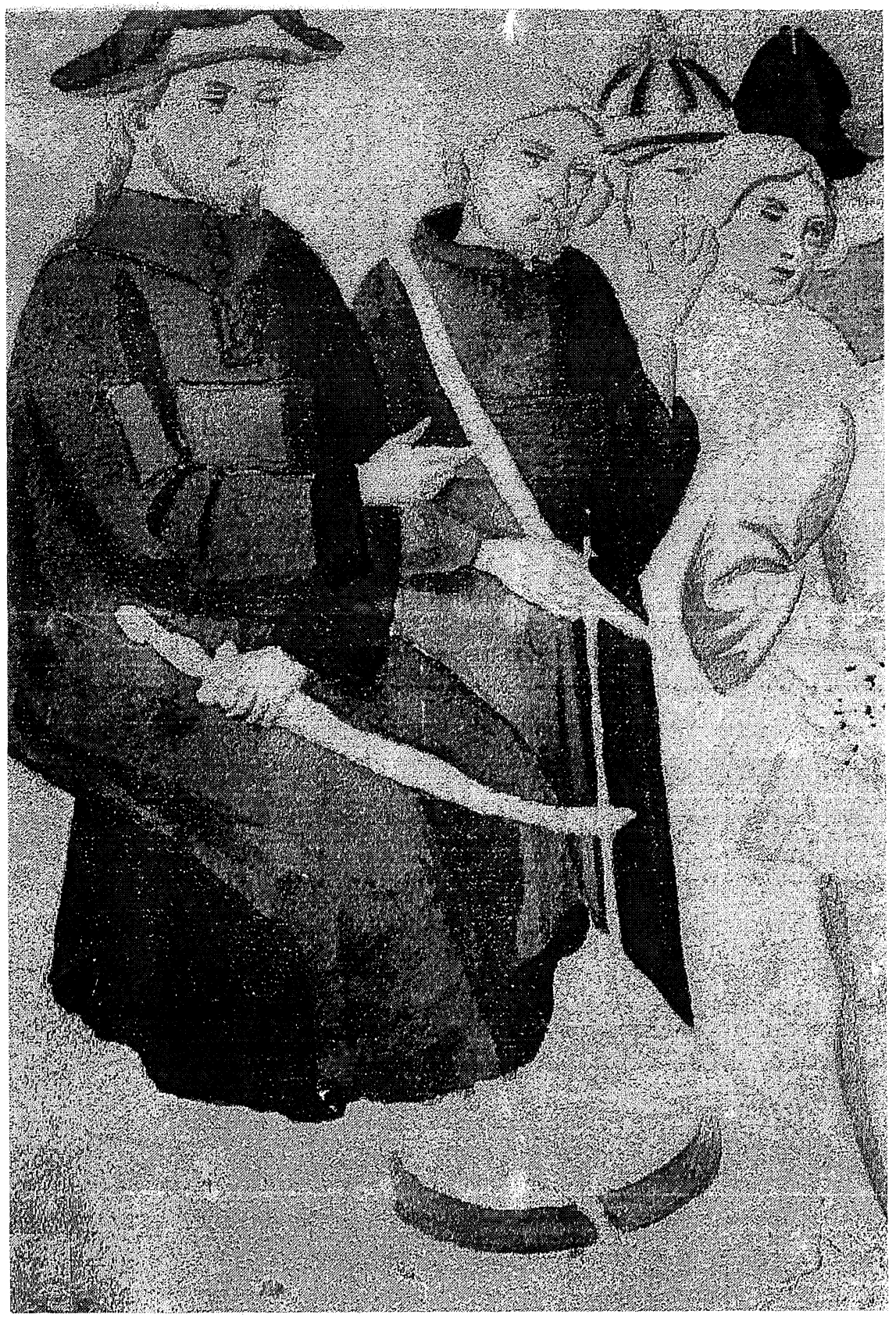

Fig. 4. Pau Milà i Fontanals. Aquarel-la inacabada. Martiri d' un Sant Bisbe. Detall. 

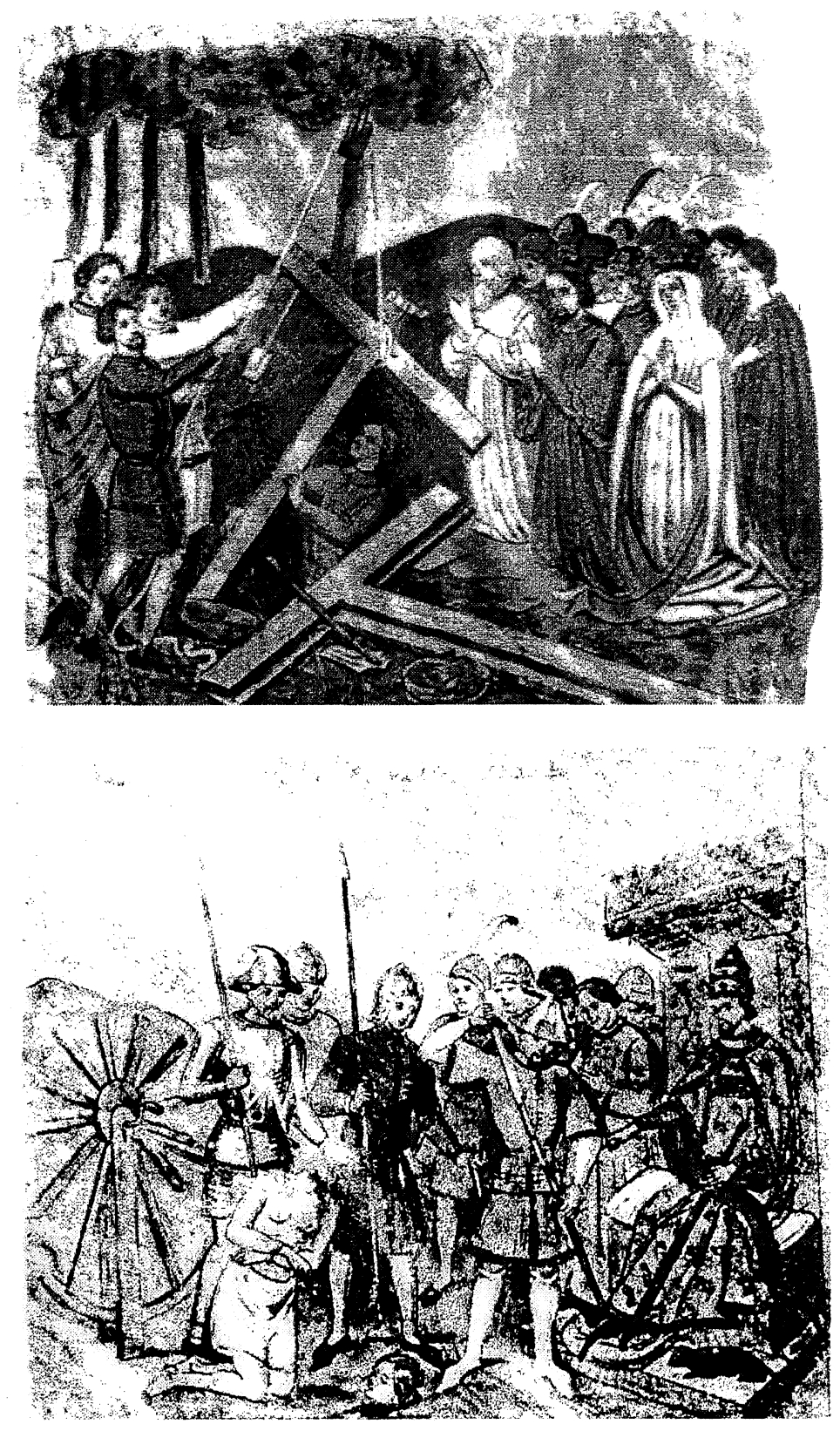

Fig. 5. Josep Puiggarí. Dos episodis del bancal de Pedralbes: Martiri de Santa Caterina i descoberta de la Vera Creu. 
L'aquarel·la de Milà està a mig fer. Sobre paper i amb el que previsiblement s'han de considerar uns colors fidels als originaris (blau clar, groc i malva), mostra l'escena de la decapitació d'un bisbe no identificat. Es indubtable que es tracta de la mateixa composició que aborda Golferichs, però, com ja ho hem assenyalat, amb una sensibilitat en aquest cas que és absent en l'altra. Es aquesta afinitat a l'estil originari el que permet descobrir darrera la pintura primitiva la mà dels Serra. Només cal comparar la cara del personatge assegut que té els peus sobre un escambell, indubtablement el que per la seva autoritat pot ordenar el martiri, així com la del que se situa a la seva esquerra, o el que figura a l'esquerra del botxi, per a constatar-ho. Es el mateix gènere de rostre que trobem dins la producció dels Serra, fins i tot coincideix el tipus d'indumentària, compresos els barrets.

Hi ha un altre tret que també entronca amb els Serra: l'escut en losange emprat a la predel la de Pedralbes, que és del tot inusual a la pintura trescentista catalana. Segons els meus coneixements, els testimonis més antics que poden adduir-se corresponen al retaule de Sixena, atribuible a un dels germans Serra, ara al MNAC, així com al del Sant Sepulcre de Saragossa, adscrit a la producció de Pere Serra ${ }^{22}$. Indubtablement, la constatació d'aquest particularisme és un nou argument a favor de la cronologia que proposem per l'obra i de la viabilitat de la seva assignació al catàleg dels Serra, probablement al de Pere, tant per les afinitats de les fesomies, com per la coincidència en determinades composicions ${ }^{23}$. D'altra banda, tot i que en l'estadi en el que es troben els nostres coneixements sobre l'obra estudiada no podem defensar la pertinença del bancal que hem estudiat al retaule major del monestir, que es confecciona durant la segona meitat del segle XIV, el que és important remarcar és la responsabilitat que Pere i Jaume Serra van tenir respecte aquest projecte. S'ha conservat la documentació que hi té a veure i ens informa de la marxa dels treballs d'ençà del 24 de novembre de 1368, moment en que se signà el corresponent contracte, fins el 12 de novembre de 1370 , en que es localitza la darrera

\footnotetext{
22J. Gudiol, S. Alcolea I Blanch, Pintura, figs. 18 i 231, 261-264.

${ }^{23} \mathrm{Hi}$ ha significatives coincidències entre la composició $\mathrm{i}$ el paisatge urbà que serveix de marc al judici del sant del retaule de Sant Llorenç de Morunys (Ibídem, fig. 265) i el corresponent a la decapitació del Sant Bisbe de la predel.la de Pedralbes. Altrament, entre la decapitació del retaule de Sogorb, atribuït al mateix pintor (Ibídem, fig. 284) i l'episodi del bancal de Pedralbes, ja mencionat.
} 
noticía que li pertoca ${ }^{24}$. Els Serra estaven vinculats a Pedralbes per mitjà de l'obra d'un retaule i potser fou l'ocasió per a encarregar-los-hi el de l'oratori privat de Constança de Cruilles. No disposem del document acreditatiu, per ara, però la cronologia i les característiques formals de l'antic bancal de Pedralbes, fan pesanr que va poder ser així.

\section{RÉSUMÉ}

Dans cet étude on suit la trace d'un fragment de retable gothique conservé jusqu'à la fin XIX $X^{\mathrm{e}}$ siècle à la sacristie du couvent de Pedralbes (Barcelona) et dont sa localisation actuelle est inconnue, compte tenu que la predelle a passée au marché antiquaire au début du $\mathrm{XIX}^{\mathrm{c}}$ siècle. Il s'agisait probablement d'une peinture des frères Serra (plus particulièrement Pere Serra) actifs en Catalogne à la deuxième moitié du XIV $v^{e}$ siècle. Divers dessins de la fin XIX ${ }^{c}$ siècle (oeuvre de Pau Milà i Fontanals. Josep Puiggarí et Macari Golferichs) constituent le point de départ de cette recherche.

\section{SUMMARY}

This article traces the history of some predella panels that had been kept at the Convent of Pedralbes until the end of the nineteenth century. Shortly thereafter, they appeared on the art market and their present location is unknown. The panels were probably the work of the Serra brothers (second half of the fourteenth century). The study and attribution are based on drawings produced at the end of the nineteenth or beginning of the twentieth century by Pau Milà i Fontanals, Josep Puiggarí and Macari Golferichs.

\footnotetext{
${ }^{24}$ Publica aquests documents: J.Ma . MAdURELL MARIMON, El pintor Lluís Borrassà. Su tiempo, sus seguidores y' sus obras, "Anales y Boletín de los Museos de Arte de Barcelona", X (1952), doc. 435, pp. 51-53; doc. 438, pp. 55-56; doc. 439, pp. 56-57; doc. 441, p. 57; 444, p. 60 .
} 